\title{
Release mortality of endangered Warsaw grouper Hyporthodus nigritus: a state-space model applied to capture-recapture data
}

\author{
Kyle W. Shertzer ${ }^{1, *}$, Nathan M. Bacheler ${ }^{1}$, G. Todd Kellison' ${ }^{1}$, John Fieberg ${ }^{2}$, \\ Robert K. Wiggers ${ }^{3}$ \\ ${ }^{1}$ National Marine Fisheries Service, Southeast Fisheries Science Center, Beaufort, North Carolina 28516, USA \\ ${ }^{2}$ Department of Fisheries, Wildlife, and Conservation Biology, University of Minnesota, St. Paul, Minnesota 55108, USA \\ ${ }^{3}$ South Carolina Department of Natural Resources, Charleston, South Carolina 29412, USA
}

\begin{abstract}
Warsaw grouper Hyporthodus nigritus is a large-bodied, deep-water, demersal fish listed on the IUCN Red List as Critically Endangered. In the USA, harvest of Warsaw grouper in recent decades has been heavily limited or prohibited. However, Warsaw grouper is part of a multispecies snapper-grouper fishery, making this species vulnerable to incidental capture (and release) as bycatch, even if not targeted for harvest. Therefore, release mortality is a primary concern for the recovery of this endangered species, especially given the potential barotraumatic effects of capture. Here, we used a long-term (11 yr) data set containing capture-recapture information on Warsaw grouper from a shallow site off the Atlantic coast of Florida. The data were collected through a citizen-science program, the South Carolina Marine Game Fish Tagging Program. We fit a state-space model to these data that accounts for-and provides estimates of release mortality as a function of length. These estimates quantify the combined effect of immediate and delayed mortality. We found that release mortality increased with length, from expected values lower than $10 \%$ to values exceeding $70 \%$. At a total length of $700 \mathrm{~mm}$, near our observed mean, the expected release mortality was $34 \%$ (95\% credible interval of 3-57\%). In general, release mortality estimates were lower than might be assumed $(\sim 100 \%)$ for a deep-water grouper. We suggest possible explanations for this result, such as the relatively shallow depth $(\sim 49 \mathrm{~m})$ of this study and the careful treatment of released fish, and conclude by discussing implications for future research and conservation.
\end{abstract}

KEY WORDS: Warsaw grouper - Release mortality · Capture-recapture - Citizen science · State-space model

\section{INTRODUCTION}

Warsaw grouper Hyporthodus nigritus generally is a deep-water, demersal apex predator distributed throughout the Gulf of Mexico and in the western Atlantic from the USA to Brazil. Life-history characteristics, such as slow growth, low productivity, and

${ }^{*}$ Corresponding author: kyle.shertzer@noaa.gov protogyny, make Warsaw grouper particularly vulnerable to overfishing (Manooch \& Mason 1987, Huntsman et al. 1999, Coleman et al. 2000, Musick et al. 2000). The American Fisheries Society categorized Warsaw grouper as being at risk of extinction in North America (Musick et al. 2000), and the International Union for Conservation of Nature (IUCN) listed

(C) J. Fieberg, R. K. Wiggers, and outside the USA the US Government 2018. Open Access under Creative Commons by Attribution Licence. Use, distribution and reproduction are unrestricted. Authors and original publication must be credited. 
this species as Critically Endangered (Chuen \& Huntsman 2006). In the USA, the Endangered Species Act listed Warsaw grouper as a 'candidate species' in 1997, and the National Oceanic and Atmospheric Administration classified Warsaw grouper as a 'species of concern' in 2004.

Warsaw grouper is (or has been) exploited commercially and recreationally. Although rare (Huntsman et al. 1999, Rudershausen et al. 2008, Farmer \& Karnauskas 2013), they are valued as an occasional trophy for sport anglers, with the largest reported fish growing over $2 \mathrm{~m}$ and reaching weights near $190 \mathrm{~kg}$ (Manooch \& Mason 1987, IGFA 1991, Parker \& Mays 1998). In the US Gulf of Mexico, harvest of Warsaw grouper is limited as part of an aggregate grouper management plan, and in Atlantic waters, possession is now entirely prohibited. However, the fisheries that capture Warsaw grouper simultaneously target multiple species associated with reefstructured habitat, and possession limits do little or nothing to curb the incidental capture and subsequent release of this species (i.e. bycatch). Consequently, release mortality is a major threat to Warsaw grouper (Chuen \& Huntsman 2006, Farmer \& Karnauskas 2013).

Release mortality can be particularly high ( 100\%) for deep-water species, due to barotrauma (Davis 2002, Rudershausen et al. 2007). As stated by Huntsman et al. (1999, p. 225), 'expanding gases during capture damage internal organs, displace eyes from their sockets, and otherwise seriously injure the fish.' That observation led them to the logical prognosis that 'establishing a bag limit for deepwater fish like speckled hind Epinephelus drummondhayi and Warsaw grouper (also a bag limit of one), which are almost certain to die upon release cannot possibly offer protection for the affected species.' We concur with the logic, but also note the lack of any previous studies attempting to estimate release mortality of Warsaw grouper.

In this study, we address 2 primary goals. The first was to develop a modeling framework to estimate release mortality from capture-recapture data. The framework is generally applicable to any species with such data, expanding on the Cormack-JollySeber (CJS) population model (Cormack 1964, Jolly 1965, Seber 1965). The second goal was to apply the model to capture-recapture data on Warsaw grouper. To our knowledge, the data set used in this study is unique, providing the only long-term (11 yr) information on individual fates of tagged Warsaw grouper. Our application allows inference about release mortality of this Critically Endangered species.

\section{MATERIALS AND METHODS}

\section{Study site and data collection}

Warsaw grouper were tagged as part of the South Carolina Marine Game Fish Tagging Program (MGFTP) administered by the South Carolina Department of Natural Resources. The MGFTP began in 1974 as a citizen science project, allowing members of the public to tag various marine and estuarine fish species (for a general description of the tagging program, see Wiggers 2010). Over 9000 recreational and commercial fishermen have tagged fish in the MGFTP, with over 134000 marine finfish being tagged in total.

We focused our analyses here on the tagging efforts of a charter captain who tagged and recaptured Warsaw grouper at a single wreck (hereafter referred to as the 'Sebastian wreck') that he discovered by happenstance in the early 1990s (R. Rincones pers. comm.). The Sebastian wreck lies in $\sim 49 \mathrm{~m}$ of water off Sebastian Inlet, Florida. The wreck was likely unknown to the general public, as the captain never saw others fishing at this location and no other fishers reported recapturing Warsaw grouper tagged there. The captain confirmed via scuba diving that the Sebastian wreck was an old shrimp trawler, surrounded by a vast expanse of sand. All Warsaw grouper were caught using heavy rod-and-reel bottom fishing gear with baited J-style hooks. Individuals were tagged with yellow nylon Hallprint dart tags inserted into the back of the fish, so that the dart interlocked with the pterygiophores. The tags included a tag number and an address to send tags for a reward (e.g. hat, T-shirt).

In southeastern US Atlantic waters from 1994 to 2011, the recreational fishing bag limit for Warsaw grouper was 1 fish vessel ${ }^{-1}$ (see Farmer \& Karnauskas 2013 for a history of management regulations). Thus, the charter captain in our study would fish at the Sebastian wreck to give his clients the opportunity to catch 1 large Warsaw grouper. If the first fish they caught was large, it was retained. However, if the captain believed a larger Warsaw grouper could be caught, he would tag and release the smaller individual using the protocol described below and continue fishing until a larger Warsaw grouper was caught. Upon capture, the length of each fish was measured, or in some cases $(\sim 15 \%)$ estimated, by the captain.

Nearly all of the captured Warsaw grouper displayed severe expansion of their swim bladders. Therefore, the captain vented all Warsaw grouper 
before release with a hollow 12-gauge cutting needle. Approximately $25 \%$ of released fish were still unable to swim to the bottom, so those fish were returned to the bottom using a homemade descender device consisting of a weight and upside-down hook with its barb removed. No Warsaw grouper floated away upon release. During each tagging and recapture event, the location, date, and length of the fish were recorded. For each recapture event, the fate of each fish was noted as retained or released with tag intact.

\section{State-space capture-recapture model with release mortality}

To quantify the biological and observation processes underlying these data, we developed a modified version of the CJS population model (Cormack 1964, Jolly 1965, Seber 1965). We implemented the model using a hierarchical state-space formulation (Gimenez et al. 2007, Royle 2008, Kéry \& Schaub 2012), which explicitly separates the state process (whether an individual is alive or dead) from the observation process (whether an individual is captured). Our primary modification was to include release mortality in the model, and a second modification accounted for the empirical feature that several fish were kept for harvest and therefore left the study.

The observed data were summarized in an $I \times T$ capture-history matrix $(\mathbf{Y})$, where $I$ is the number of tagged individuals and $T$ is the number of capture occasions. The matrix entry $y_{i, t}=1$ if individual $i$ is observed on occasion $t$, and $y_{i, t}=0$ otherwise. Because individuals must be captured initially to be included in this data set, the first entry $(t=1)$ for each fish was $y_{i, t}=1$. As sampling was opportunistic, we used a time step of $30 \mathrm{~d}$ to define $\mathrm{T}=20$ capture occasions, with recaptures occurring within the first $30 \mathrm{~d}$ assigned to $t=2$, within the next $30 \mathrm{~d}$ to $t=3$, and so forth.

The state process was summarized by a latent variable $z_{i, t}$, where $z_{i, t}=1$ if individual $i$ is alive at time $t$, and $z_{i, t}=0$ if it is dead. Thus, matrix $\mathbf{Z}$ defines the true state of each individual over time, which is only partially observed. Individuals were treated as known alive at first capture and known dead after subsequent recaptures if they were kept. Otherwise, the states were modeled probabilistically as Bernoulli trials:

$$
z_{i, t+1} \mid z_{i, t} \sim \operatorname{Bernoulli}\left(\theta_{i, t+1}\right)
$$

where $\theta_{i, t+1}$ is the probability that an individual survives until time $t+1$ conditional on being alive at time $t$. This probability is defined as

$$
\theta_{i, t+1}=\left(1-\kappa_{i, t}\right)\left[\left(1-y_{i, t}\right)\left(\phi_{1} z_{i, t}\right)+y_{i, t} \phi_{2} z_{i, t}\right]
$$

Here, $\kappa_{i, t}$ is an indicator variable that equals 1 if an individual of any size is kept for harvest at any time $\leq t$ and equals 0 otherwise; $\phi_{1}$ is the probability that a tagged individual remains vulnerable to capture in the next time period given that it was not captured in this time period; and $\phi_{2}$ is the similar probability that applies if an individual is captured. Eq. (2) ensures that, if an individual is dead at time $t=\tau$, then $\theta_{i, t+1}=0$ and therefore $z_{i, t}>\tau=0$ at all subsequent times.

The probability $\phi_{1}$ represents the product of multiple probabilities, including survival $\left(S_{1}\right)$ of natural mortality processes, tag retention $(R)$, and site fidelity ( $F_{\text {; }}$ i.e. not emigrating): $\phi_{1}=S_{1} \times R \times F$. The probability $\phi_{2}$ includes those same probabilities and also the probability of surviving release $\left(S_{2}\right): \phi_{2}=$ $S_{1} \times R \times F \times S_{2}=\phi_{1} \times S_{2}$. Because the model applies a time step of $30 \mathrm{~d}, S_{2}$ accounts not only for immediate release mortality but also delayed mortality, which can be substantial in similar fisheries (Rudershausen et al. 2007). Although $S_{1}, R$, and $F$ cannot be separated without additional information, survival $S_{2}$ is estimable as $S_{2}=\phi_{2} / \phi_{1}$. Thus, the probability of release mortality $(\delta)$ can be estimated by the relationship,

$$
\delta=1-\left(\phi_{2} / \phi_{1}\right)
$$

An implicit assumption behind Eq. (3) is that rates of tag shedding and emigration are the same for individuals experiencing $\phi_{1}$ and for those experiencing $\phi_{2}$. In other words, those rates are assumed not to be affected by capture itself.

We modeled the probabilities $\phi_{1}$ and $\phi_{2}$ as logistic functions of length:

$$
\begin{gathered}
\phi_{1}=\exp \left(\alpha+\beta L_{i, t}\right) /\left[1+\exp \left(\alpha+\beta L_{i, t}\right)\right] \\
\phi_{2}=\exp \left(\alpha+\gamma+\beta L_{i, t}\right) /\left[1+\exp \left(\alpha+\gamma+\beta L_{i, t}\right)\right]
\end{gathered}
$$

where $\alpha, \beta$, and $\gamma$ are estimated parameters, and $L_{i, t}$ is the length of individual $i$ at time $t$. Because $L_{i, t}$ could only be measured when a fish was captured, we imputed values for sampling occasions when unobserved. This was accomplished in 1 of 2 ways. If a fish was observed at a later sampling occasion, lengths were linearly interpolated between observations. If not, the mean growth rate $\left(0.49 \mathrm{~mm} \mathrm{~d}^{-1}\right)$ was applied until the last capture period $(t=20)$, with length truncated at the maximum observed measurement to avoid extrapolating beyond the range of data. We 
computed the mean growth rate as the arithmetic average growth of all fish recaptured at least once. This process provided a matrix (L) representing the length of each fish at each sampling occasion. For use in the capture-recapture model, matrix entries were standardized to have a mean of 0 and a standard deviation of 1 .

If an individual is alive at time $t>1$, it might be recaptured with probability $p$. Similar to survival, the observation process was modeled probabilistically as Bernoulli trials:

$$
y_{i, t} \mid z_{i, t} \sim \operatorname{Bernoulli}\left(z_{i, t} p\right)
$$

where the probability of being captured (observed) is conditional on being alive.

This model has 4 parameters: $\alpha, \beta, \gamma$, and $p$. For $\alpha$ and $\beta$, we specified normal prior distributions, $\alpha \sim N(0,10)$ and $\beta \sim N(0,10)$. For $\gamma$, we specified a halfnormal prior distribution, with $\gamma=-\left|\gamma^{\prime}\right|$ and $\gamma^{\prime} \sim \mathrm{N}(0,10)$. This ensured that $\gamma$ was non-positive, which constrained $\phi_{2} \leq \phi_{1}$, necessary because $\phi_{2}$ included an additional source of mortality $(\delta)$. For $p$, we specified a uniform prior distribution, $p \sim U(0,1)$. Our primary interest lay in characterizing the posterior distribution of $\delta$, i.e. the probability of release mortality as a function of length.

The model was implemented in a Bayesian framework using JAGS version 4.2.0 (Plummer 2003). We applied JAGS via $\mathrm{R}$ version 3.3.3 (R Core Team 2017), relying on the R package R2jags (Su \& Yajima 2015). We ran 3 independent Markov chains, each for 250000 iterations, and with a burn-in period of 50000 iterations to avoid any influence of starting values. Posterior distributions were computed after thinning the resulting chains by keeping every fifth

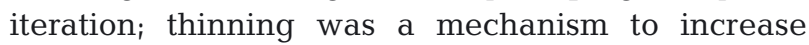
chain length for improved convergence, while simultaneously minimizing computational storage space (Link \& Eaton 2012). We assessed convergence qualitatively by visual inspection of trace, density, and autocorrelation plots, and quantitatively by inspecting the Brooks-Gelman-Rubin statistic for values close to 1 (Brooks \& Gelman 1998).

\section{RESULTS}

A total of 196 Warsaw grouper were tagged at the Sebastian wreck within a 10 yr period. The first Warsaw grouper were tagged on 10 November 1994, and the last individual was tagged on 31 January 2004. Most of these Warsaw grouper (88\%) were tagged within a 5 yr period from 1994 to 1998 (Fig. 1A). War-

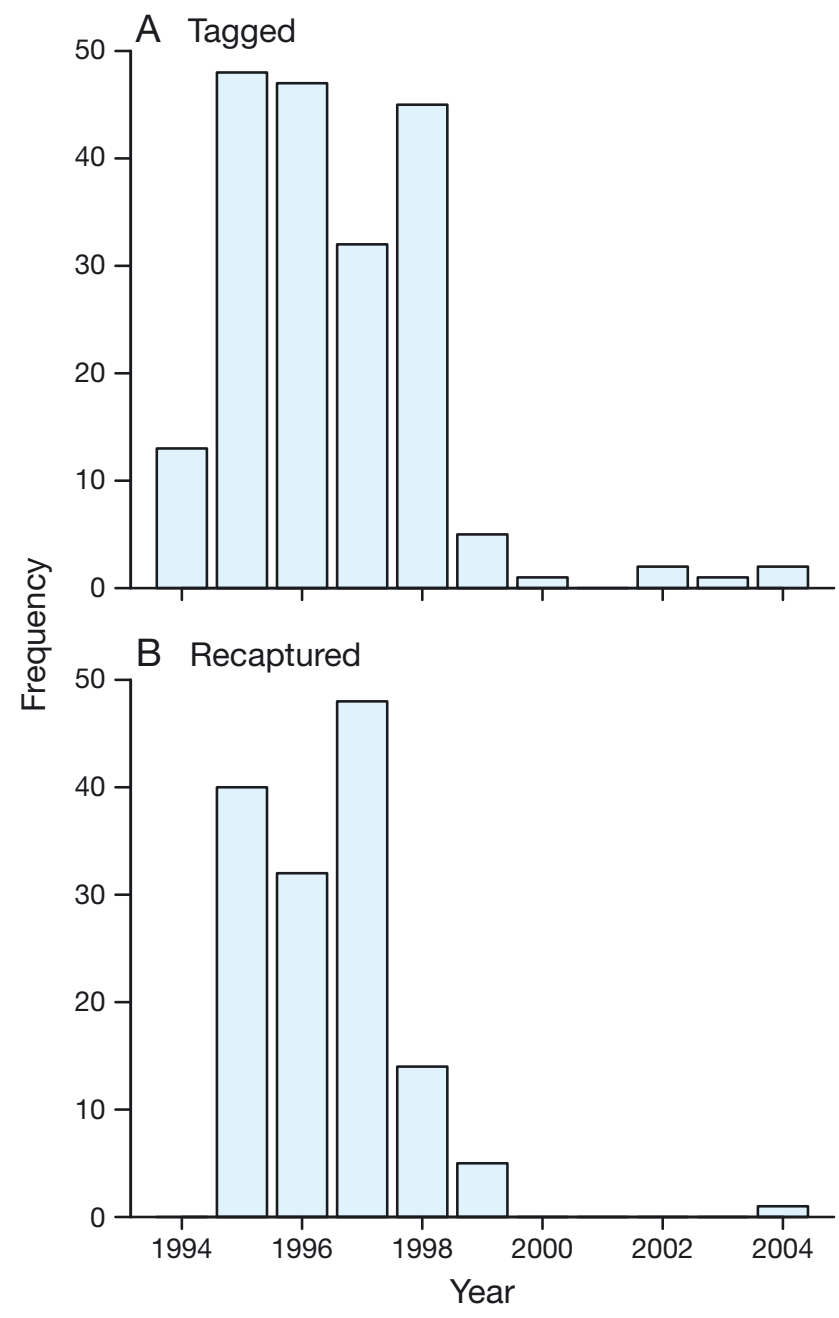

Fig. 1. Annual frequency of (A) tagged and (B) recaptured Warsaw grouper Hyporthodus nigritus caught at the Sebastian wreck, which lies in $\sim 49$ m of water off Sebastian Inlet, on the Atlantic coast of Florida, USA

saw grouper that were measured at tagging $(n=171)$ ranged in size from 457 to $1003 \mathrm{~mm}$ total length $($ mean $\pm \mathrm{SE}=695 \pm 9 \mathrm{~mm}$; Fig. 2A).

Of the 196 Warsaw grouper tagged at the Sebastian wreck, $71(36 \%)$ were recaptured at least once. Of these 71 individuals, 30 were recaptured exactly 1 time, 24 were recaptured 2 times, 10 were recaptured 3 times, 5 were recaptured 4 times, 1 was recaptured 5 times, and 1 was recaptured 6 times. Thus, 139 recapture events occurred in total. Given that $36 \%$ of all tagged Warsaw grouper were recaptured, the ostensible release mortality in this study was at most $64 \%$. Warsaw grouper were recaptured between 7 February 1995 and 19 June 2004, with most (96\%) being recaptured in a $4 \mathrm{yr}$ window between 1995 and 1998 (Fig. 1B). Of the 139 recaptured Warsaw grouper, 109 were measured at recapture and ranged 


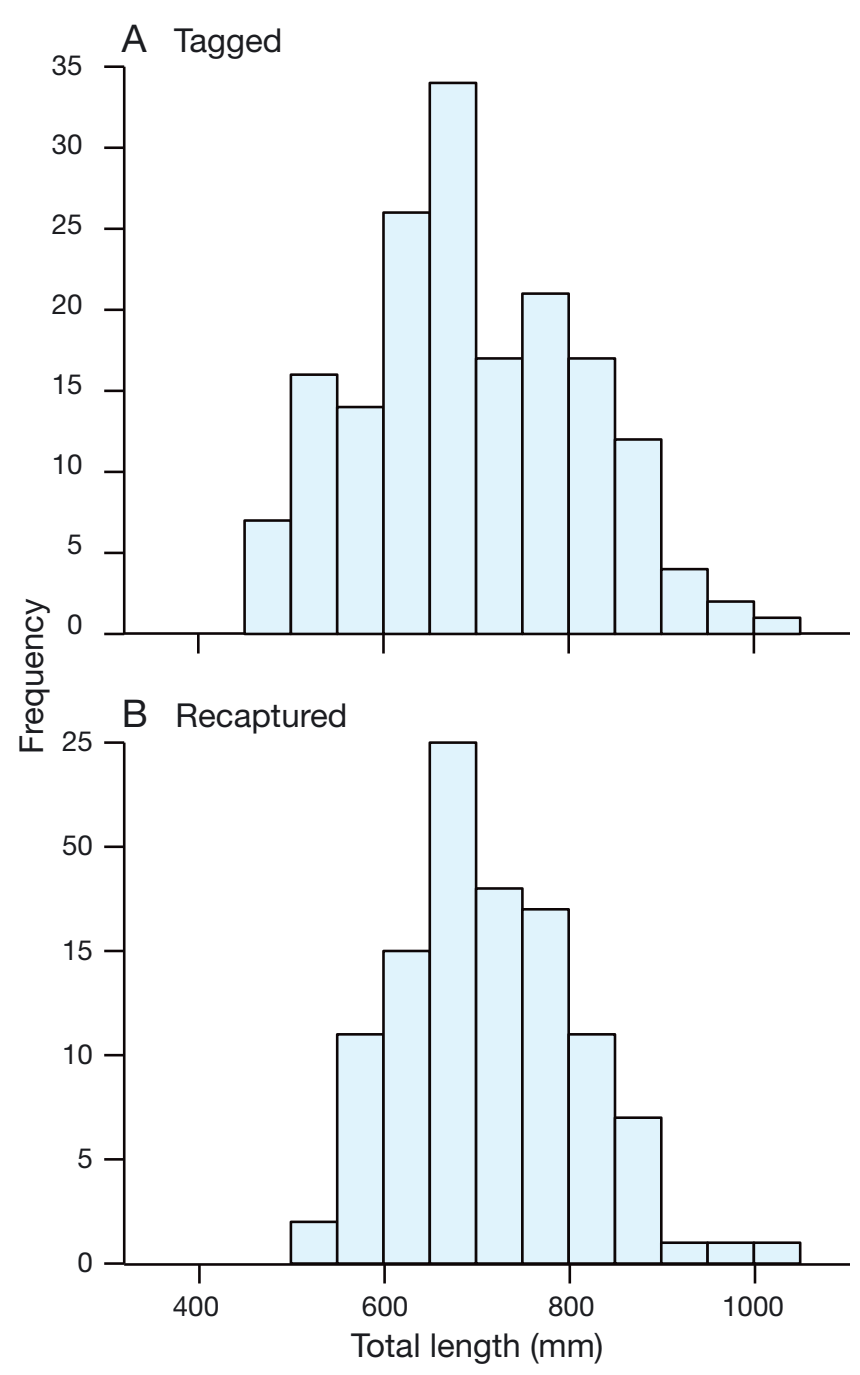

Fig. 2. Size frequency of (A) tagged and (B) recaptured Warsaw grouper Hyporthodus nigritus caught at the Sebastian wreck, which lies in $\sim 49 \mathrm{~m}$ of water off Sebastian Inlet (At lantic coast of Florida, USA)

from 533 to $1029 \mathrm{~mm}$ total length (mean $\pm \mathrm{SE}=718 \pm$ $9 \mathrm{~mm}$; Fig. 2B). The time between tagging and first recapture ranged from 7 to $442 \mathrm{~d}$, and the longest time between the initial tagging and final recapture was $542 \mathrm{~d}$. This duration, given our $30 \mathrm{~d}$ time step, led us to use $T=20$ capture occasions with at least 1 recapture in the last column of the capture-history matrix.

In the model, the posterior median parameter values (95\% credible intervals) were $\alpha=1.95$ (1.28, 3.99), $\beta=-0.86(-1.20,-0.55), \gamma=-2.23(-5.06,-0.24)$, and $p=0.17(0.11,0.24)$. Being strictly negative, the credible interval of $\beta$ excluded 0 , indicating that length was an important predictor of these capturerecapture data. The posterior median odds ratio, $\exp (\beta)$, was $0.42(0.30,0.58)$, suggesting the odds of a fish remaining in the system decreased by a factor of 0.42 for every $1 \mathrm{SD}$ (133 mm) increase in length.
As indicated by an odds ratio $<1$, the probabilities $\phi_{1}$ and $\phi_{2}$ decreased with length (Fig. 3A,B). The median posterior value of $\phi_{1}$ was near 1 for fish $<700 \mathrm{~mm}$ and decreased to a value near 0.7 at $1000 \mathrm{~mm}$, with credible intervals widening as length increased. The median posterior value of $\phi_{2}$ had a shape similar to $\phi_{1}$, but decreased more quickly with size (the effect of parameter $\gamma$ ) and had wider credible intervals. The estimated release mortality increased with length (Fig. 3C), from a median posterior value $(95 \%$ credible interval) of $0.07(0.00,0.20)$ near $400 \mathrm{~mm}$ to $0.71(0.11,0.92)$ near $1000 \mathrm{~mm}$. At $700 \mathrm{~mm}$, which is near the observed mean and midpoint of the range, the expected release mortality was $0.34(0.03,0.57)$.

\section{DISCUSSION}

Similar to Thorson et al. (2014), our study used citizen-science data to better understand an endangered grouper species. Citizen-science data programs have become well recognized in ecological conservation as valuable complements to hypothesisdriven research and monitoring (Brewer 2002, Devictor et al. 2010, Dickinson et al. 2010). Such data are relatively inexpensive to collect, lead to a more engaged and informed public, and can increase sampling coverage beyond the capacity of resourcelimited scientific surveys. As these programs gain popularity, we expect to see accompanying benefits for natural resource management and conservation, particularly for rare marine species that are otherwise difficult to observe.

Our state-space formulation expanded the CJS population model to include release mortality. With only 4 time-invariant parameters $(\alpha, \beta, \gamma$, and $p)$ to estimate, the model is relatively simple. Its primary purpose was to quantify release mortality as a function of fish length, given the data we had available. The basic modeling framework is readily adaptable, and simple modifications could accommodate other data sources that might help refine the estimates of release mortality or make inferences on other state or observation processes.

Although the model estimated capture probability $(p)$, future field studies might improve the analysis by providing external information on this parameter, ideally as a function of size. For example, the use of underwater video cameras or scientific divers could provide estimates of local abundance (e.g. Shertzer et al. 2016), which in turn would shed light on capture or detection probability of other sampling meth- 

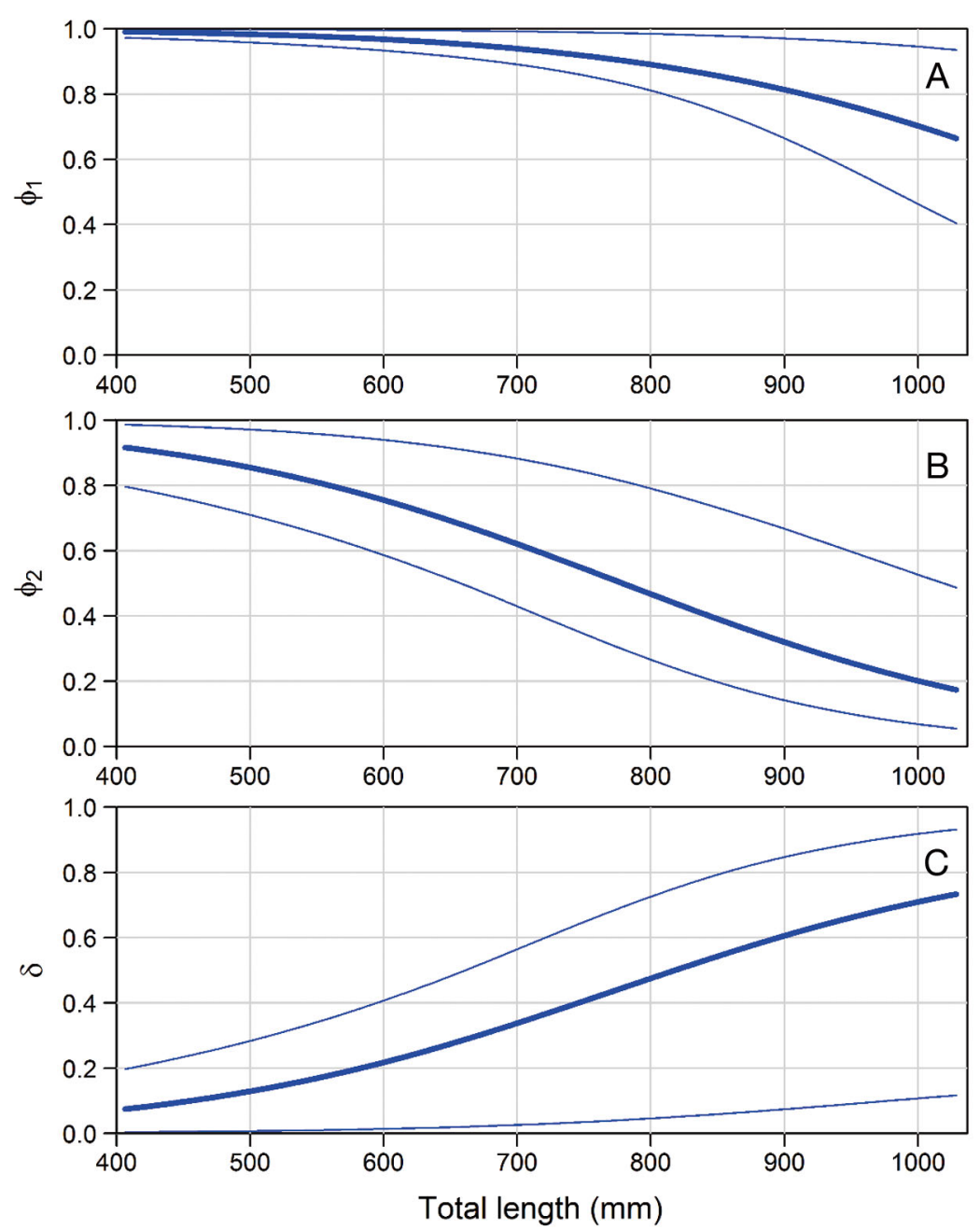

Fig. 3. Model predictions of (A) probability $\phi_{1}$, (B) probability $\phi_{2}$, and (C) release mortality $\delta$, each as a function of length of Warsaw grouper $\mathrm{Hy}$ porthodus nigritus, where $\phi_{1}$ is the probability that a tagged individual remains vulnerable to capture in the next time period given that it was not captured in this time period, and $\phi_{2}$ is the similar probability that applies if an individual is captured. Standardized sizes, as used in the analysis, were translated back to their original scale for this figure. Thick lines indicate posterior median values, and thin lines indicate $95 \%$ credible intervals. The model time step was $30 \mathrm{~d}$

ods. That information could then be used to validate the current estimate, included quantitatively as an informative Bayesian prior distribution, or modeled simultaneously in an integrated population modeling framework.

Model estimates of probability $\phi_{1}$ were high, particularly for smaller fish (Fig. 3A). Given the current data set, the model cannot separate the various processes that comprise $\phi_{1}$, namely survival $\left(S_{1}\right)$ of natural mortality processes, tag retention, and site fidelity. However, we would expect survival $S_{1}$ to approach 1.0, given that the model applied a $30 \mathrm{~d}$ time step and that Warsaw grouper is a relatively long-lived species, with the maximum observed age of $41 \mathrm{yr}$ (Manooch \& Mason 1987). Thus, decreasing values of $\phi_{1}$ with size likely reflect tag loss or emigration. Future field studies could separate those sources of loss using double tagging (tag loss) or telemetry (emigration) approaches.

Little is known about migration patterns of Warsaw grouper. Some species of Atlantic grouper are believed to display ontogenetic shifts as they mature, with larger fish disproportionately observed or caught in deeper water. Such shifts may well occur, but we note that similar observations could also result from greater fishing pressure truncating the age structure in shallower waters. Most reef-associated fishes show high site fidelity, and several grouper species are known to form consistent spawning aggregations (Coleman et al. 2000). Collins (2014) quantified migration patterns of another large-bodied, protected species - goliath grouper Epinephelus itajara - found in the southeastern USA. In that study, individuals stayed primarily at a single reef, but many $(72 \%)$ were absent during the spawning season for periods exceeding $7 \mathrm{~d}$, and almost all (82\%) eventually returned to their initial tagging site (Collins 2014). McGovern et al. (2005) analyzed tag-recapture data of a smaller grouper, gag Mycteroperca microlepis, and found that many (36\%) recaptured fish moved little, but some $(23 \%)$ moved long distances $(>185 \mathrm{~km})$. For grouper species in general, a better understanding of complex migration patterns and spawning behavior could inform both population models and fishery management.

Although a better understanding of migration (also natural mortality and tag retention) would be valuable, separating $\phi_{1}$ into its component processes is unnecessary for our expanded CJS model to estimate release mortality. This is because those same components also comprise $\phi_{2}$ and therefore their effects cancel when estimating release mortality (Eq. 3). An underlying assumption is that the components are not affected by recapture itself. If that assumption were faulty and recapture induced tag shedding or emigration, the model would interpret those losses as 
release mortality, and our estimates of $\delta$ would be biased high.

In our model, larger Warsaw grouper experienced higher release mortality than smaller fish. This result is not general across species. Studies of other species have reported a similar relationship of release mortality increasing with size (Bartholomew \& Bohnsack 2005, Pulver 2017), but also a decreasing relationship or no effect (Davis 2002, Bartholomew \& Bohnsack 2005, Stephen \& Harris 2010, Pulver 2017). Specific to other grouper species, Pulver (2017) found an increasing relationship with size for gag and red grouper E. morio, but no detectable effect for scamp $M$. phenax and speckled hind E. drummondhayi. Collins (2014) found no effect of size on barotrauma for goliath grouper. The range of sizes measured in our study $(457-1029 \mathrm{~mm})$ is consistent with the general range of sizes ( $\sim 500-1100 \mathrm{~mm})$ reported for the commercial fishery in this region (SEDAR 2004), and although larger asymptotic lengths have been reported (Manooch \& Mason 1987), fish much larger than our observed range appear to be rare. A recent examination of age and length data $(n=187)$ from the NOAA Beaufort Laboratory found an asymptotic average length near $1000 \mathrm{~mm}$ (unpublished study).

The barotraumatic capture of deep-water marine fish results in release mortality that is typically assumed to be very high. Recent stock assessments of deep-water fishes in our study region, including tilefish Lopholatilus chamaeleonticeps, blueline tilefish Caulolatilus microps, and snowy grouper Hyporthodus niveatus, have assumed a release mortality of $100 \%$ (stock assessment reports available, http:// sedarweb.org). We had expected similarly high values for the endangered Warsaw grouper, but instead found evidence in our data set that release mortality was considerably lower.

One possible explanation for the low estimates of release mortality is the relatively shallow depth $(\sim 49 \mathrm{~m})$ of our study site. Farmer \& Karnauskas (2013, p. 9) found that Warsaw grouper is 'heavily associated with the shelf-edge between 25-100 fathoms (45.7-182.9 meters) on hardbottom habitats.' This range is generally consistent with Manooch \& Mason (1987, p. 66), who reported that the 'species inhabits irregular bottom of the continental shelf break in waters of 76 to $219 \mathrm{~m}$ deep.' Nearly all of the captured Warsaw grouper in our study displayed severe expansion of their swim bladders, yet it remains possible that the effects of barotrauma would be more detrimental at greater depths. Although the effect of capture depth varies by species (Bartholomew \& Bohnsack 2005), barotrauma or release mortality generally increases with depth for most groupers, including gag (Sauls 2014, Pulver 2017), goliath grouper (Collins 2014), red grouper (Wilson \& Burns 1996, Pulver 2017), scamp (Wilson \& Burns 1996, Pulver 2017), and speckled hind (Pulver 2017).

We frame our study as the first of its kind for this species, but until additional studies can verify or contextualize our findings, we caution against extrapolating our unexpectedly low estimates of release mortality to the population level. The depth of our study site and conscientious fishing practices of the captain may not be representative of the fishery in general; greater depths and poor handling of captured fish could result in higher values of release mortality (Bartholomew \& Bohnsack 2005). Nonetheless, our findings are encouraging, suggesting strong potential to achieve a lower release mortality rate than is currently assumed for Warsaw grouper and perhaps other deep-water fishes. Indeed, venting can be effective if properly performed (Bartholomew \& Bohnsack 2005, Drumhiller et al. 2014), and descender devices have been shown to increase release survival of snappers (Drumhiller et al. 2014) and deep-water groupers (Runde \& Buckel in press). Widespread adoption of conscientious release methods could benefit the management and conservation of deep-water species immensely.

Acknowledgements. We thank T. Arnold, M. Kéry, and M. Schaub for comments on the model, Captain R. Rincones for providing data on tagged Warsaw grouper, and J. Buckel, H. Flowers, E. Williams, and anonymous referees for reviewing the manuscript.

\section{LITERATURE CITED}

Bartholomew A, Bohnsack JA (2005) A review of catch-andrelease angling mortality with implications for no-take reserves. Rev Fish Biol Fish 15:129-154

Brewer C (2002) Outreach and partnership programs for conservation education where endangered species conservation and research occur. Conserv Biol 16:4-6

Brooks S, Gelman A (1998) General methods for monitoring convergence of iterative simulations. J Comput Graph Stat 7:434-455

Chuen NW, Huntsman G (2006) Hyporthodus nigritus. The IUCN Red List of Threatened Species 2006: e.T7860 A12857446

Coleman FC, Koenig CC, Huntsman GR, Musick JA, Eklund AM, McGovern JC, Grimes CB (2000) Long-lived reef fishes: the grouper-snapper complex. Fisheries 25:14-21

Collins A (2014) An investigation into the habitat, behavior and opportunistic feeding strategies of the protected Goliath grouper (Epinephelus itajara). PhD dissertation, University of South Florida, Tampa, FL

Cormack RM (1964) Estimates of survival from the sighting of marked animals. Biometrika 51:429-438 
Davis M (2002) Key principles for understanding fish bycatch discard mortality. Can J Fish Aquat Sci 59: 1834-1843

* Devictor V, Whittaker RJ, Beltrame C (2010) Beyond scarcity: citizen science programmes as useful tools for conservation biogeography. Divers Distrib 16:354-362

* Dickinson JL, Zuckerberg B, Bonter DN (2010) Citizen science as an ecological research tool: challenges and benefits. Annu Rev Ecol Evol Syst 41:149-172

Drumhiller KL, Johnson MW, Diamond SL, Reese Robillard MR, Stunz GW (2014) Venting or rapid recompression increase survival and improve recovery of red snapper with barotrauma. Mar Coast Fish 6:190-199

Farmer NA, Karnauskas M (2013) Spatial distribution and conservation of speckled hind and warsaw grouper in the Atlantic ocean off the Southeastern U.S. PLOS ONE 8:e78682

Gimenez O, Rossi V, Choquet R, Dehais C and others (2007) State-space modelling of data on marked individuals. Ecol Modell 206:431-438

Huntsman GR, Potts J, Mays RW, Vaughan D (1999) Groupers (Serranidae, Epinephelinae): endangered apex predators of reef communities. Am Fish Soc Symp 23: $217-231$

IGFA (International Game Fish Association) (1991) World record game fishes. International Game Fish Association, Dania Beach, FL

Jolly GM (1965) Explicit estimates from capture-recapture data with both death and immigration-stochastic model. Biometrika 52:225-247

Kéry M, Schaub M (2012) Bayesian population analysis using WinBUGS: a hierarchical perspective. Academic Press, Waltham, MA

Link WA, Eaton MJ (2012) On thinning of chains in MCMC. Methods Ecol Evol 3:112-115

Manooch CS III, Mason DL (1987) Age and growth of the Warsaw grouper and black grouper from the southeast region of the United States. Northeast Gulf Sci 9:65-75

McGovern JC, Sedberry GR, Meister HS, Westendorff TM, Wyanski DM, Harris PJ (2005) A tag and recapture study of gag, Mycteroperca microlepis, off the southeastern U.S. Bull Mar Sci 76:47-59

Musick JA, Harbin MM, Berkeley SA, Burgess GH and others (2000) Marine, estuarine, and diadromous fish stocks at risk of extinction in North America (exclusive of Pacific salmonids). Fisheries 25:6-30

Parker RO, Mays RW (1998) Southeastern U.S. deepwater reef fish assemblages, habitat characteristics, catches, and life history summaries. Tech Rep NMFS 138. US Department of Commerce, NOAA, Seattle, WA

Plummer M (2003) JAGS: a program for analysis of Bayesian graphical models using Gibbs sampling. In: Hornik K, Leisch F, Zeileis A (eds) Proceedings of the $3^{\text {rd }}$ International Workshop on Distributed Statistical Computing, Vienna, Austria. https://www.r-project.org/conferences/ DSC-2003/Proceedings/Plummer.pdf

Editorial responsibility: Eric Gilman,

Honolulu, Hawaii, USA
Pulver JR (2017) Sink or swim? Factors affecting immediate discard mortality for the Gulf of Mexico commercial reef fish fishery. Fish Res 188:166-172

R Core Team (2017) R: a language and environment for statistical computing. R Foundation for Statistical Computing, Vienna

Royle JA (2008) Modeling individual effects in the CormackJolly-Seber model: a state-space formulation. J Int Biom Soc 64:364-370

Rudershausen PJ, Buckel JA, Williams EH (2007) Discard composition and release fate in the snapper and grouper commercial hook-and-line fishery in North Carolina, USA. Fish Manage Ecol 14:103-113

Rudershausen PJ, Williams EH, Buckel JA, Potts JC, Manooch CS III (2008) Comparison of reef fish catch per unit effort and total mortality between the 1970s and 2005-2006 in Onslow Bay, North Carolina. Trans Am Fish Soc 137:1389-1405

Runde BJ, Buckel JA (in press) Descender devices are promising tools for increasing survival in deepwater groupers. Mar Coast Fish

Sauls B (2014) Relative survival of gags Mycteroperca microlepis released within a recreational hook-and-line fishery: application of the Cox Regression Model to control for heterogeneity in a large-scale mark-recapture study. Fish Res 150:18-27

* Seber GAF (1965) A note on the multiple-recapture census. Biometrika 52:249-259

SEDAR (SouthEast Data, Assessment, and Review) (2004) SEDAR 4: Stock assessment of the deepwater snappergrouper complex in the South Atlantic. SouthEast Data, Assessment, and Review, North Charleston, SC

Shertzer KW, Bacheler NM, Coggins LG Jr, Fieberg J (2016) Relating trap capture to abundance: a hierarchical statespace model applied to black sea bass (Centropristis striata). ICES J Mar Sci 73:512-519

* Stephen JA, Harris PJ (2010) Commercial catch composition with discard and immediate release mortality proportions off the southeastern coast of the United States. Fish Res 103:18-24

* Su YS, Yajima M (2015) R2jags: using R to Run 'JAGS'. R package version $0.5-7$. https://cran.r-project.org/package $=$ R2jags

Thorson JT, Scheuerell MD, Semmens BX, Pattengill-Semmens CV (2014) Demographic modeling of citizen science data informs habitat preferences and population dynamics of recovering fishes. Ecology 95:3251-3258

*Wiggers RK (2010) South Carolina marine game fish tagging program 1978 - 2009. South Carolina Department of Marine Resources Division. www.dnr.sc.gov/marine/ tagfish/pdf/TaggingProgram2010.pdf (accessed 3 April 2017)

Wilson RR, Burns KM (1996) Potential survival of released groupers caught deeper than $30 \mathrm{~m}$ based on shipboard and in-situ observations, and tag-recapture data. Bull Mar Sci 58:234-247

Submitted: May 23, 2017; Accepted: October 21, 2017 Proofs received from author(s): December 11, 2017 